\title{
Treatment options for ocular adnexal lymphoma (OAL)
}

This article was published in the following Dove Press journal:

Clinical Ophthalmology

24 November 2009

Number of times this article has been viewed

\section{Victoria Mary Lendrum Cohen}

St. Bartholomew's and Moorfields Eye Hospital, London UK

Correspondence: Victoria Cohen Consultant Ocular Oncologist, St. Bartholomew's and Moorfields Eye Hospital, West Smithfield, London ECIA 7BE, UK Email: victoria.lendrum@gmail.com
Abstract: Most lymphomas that involve the ocular adnexal structure are low grade, B cell, non-Hodgkin's lymphomas. The treatment depends upon the grade and stage of the disease. High grade lymhoma requires treatment with systemic chemotherapy whereas the localized low grade (extranodal marginal zone lymphoma) can be successfully managed with local radiotherapy. Chlamydia psittaci infection is associated with low grade ocular lymphoma; however there is wide geographic variation in the strength of this association. Blanket antibiotic therapy is not advised unless there is proof of an infective agent. The monoclonal antibody, rituximab, may be successful for CD20 positive lymphoma, although it is likely that rituximab will have better long-term results when used in combination with systemic chemotherapy.

Keywords: ocular adnexal lymphoma, mucosa associated lymphoid tissue, extranodal marginal zone lymphoma, Chlamydia psittaci, rituximab, radiotherapy, chemotherapy

\section{Treatment options for ocular adnexal lymphoma (OAL)}

OAL comprises lymphoma that affects the orbit, lid, lacrimal gland and conjunctiva. The treatment of lymphoma depends on the type, location and stage of the disease. The majority (50\%-90\%) of OAL is low-grade mucosa associated lymphoid tissue (MALT) lymphoma. According to the World Health Organization modification of the REAL classification, MALT lymphoma is classified as extranodal marginal zone lymphoma (EMZL). The other 4 main types of OAL are follicular cell, mantle cell, diffuse large B cell (DLBCL) and lymphoplasmacytic lymphoma. They are all B cell, non-Hodgkin's lymphoma, the subtype derived from various stages of B cell maturation. The new classification of lymphoma is dependent on histological, immunophenotypic and molecular genetic analysis. Hodgkin's lymphoma does not affect the ocular adnexal structures unless there is widespread systemic involvement or a history of previous systemic Hodgkin's lymphoma.

According to the Ann-Arbor staging system lymphoma confined to the orbit is designated as stage I, involvement of adjacent structures (sinuses, tonsil and nose) is stage II. Stage III is abdominal nodal disease below the diaphragm and IV by definition refers to disseminated involvement of one or more extra-nodal sites (eg, liver, bone) and "E" is used when there is a local extra-nodal extent (eg, IE, IIE, IIIE and IVE). Approximately $20 \%$ of the patients will have stage III or IV disseminated involvement. The grading system is similar to nodal lymphomas.

Broadly speaking, OAL with systemic involvement requires systemic treatments whereas low-grade (EMZL or follicular cell) lymphoma localized to the eye can be 
very successfully managed with local treatments such as cryotherapy, surgical excision or external beam radiotherapy. When considering local treatment it is important to exclude bilateral ocular involvement. Even in the absence of clinical signs an MRI of both orbits may reveal a contralateral retroorbital mass lesion. Recurrence in contralateral orbit is seen in $>10 \%$ of patient with orbital lymphoma.

Staging investigations should include full blood count, hepatic enzymes including LDH, CT abdomen, chest and pelvis, MRI or CT of the orbits, and a bone marrow biopsy and aspirate.

\section{Observation}

This is only appropriate for low-grade lymphoma localized to the conjunctiva or orbit with no systemic involvement. A biopsy is required to grade the lymphoma.

\section{Surgery and cryotherapy}

Surgical excision or cryotherapy is most appropriate for localized stage 1 conjunctival EMZL/MALT lymphoma. ${ }^{1}$ This is not curative treatment but can control local disease and relieve local symptoms. Tanimoto et $\mathrm{al}^{2}$ reported very good local control of stage 1 MALT lymphoma following biopsy or surgical resection alone. Patients were followed for a median of 7.1 years, $69 \%$ of patients did not require any further treatment. The estimated overall survival rates were $94 \%$ at 10 years and $71 \%$ at 15 years. ${ }^{2}$ Although, patients should be closely followed for recurrence, histological transformation of the tumor and long-term systemic manifestations of lymphoma.

\section{Radiotherapy}

This has been the mainstay of treatment for localized OAL for many years with excellent control rates. Central nervous system prophylactic radiotherapy is not required as metastatic intraocular or brain involvement is rare. ${ }^{3}$ The dose of radiation is tapered according to the grade of the lymphoma, 28 to 36 Gy for low-grade lymphoma and 30 to 40 Gy for high-grade. EMZL, lymphoplasmacytic and follicular cell lymphoma are considered low grade, whereas DLBCL and mantle cell are high-grade lymphomas. Five-year local control rates for EMZL and follicular lymphoma after a dose of more than 30 Gy reach $100 \% .{ }^{4}$ However, high rates of delayed systemic recurrence suggest long-term follow up studies are required to assess the true benefit of radiotherapy. ${ }^{5}$

There is ongoing debate about use of lens shielding radiotherapy to protect the lens from cataract formation. Some studies show no effect on local recurrence, whereas in others all recurrences have occurred in patients whose lenses were shielded. ${ }^{6,7}$ Partial orbit volume irradiation leads to unacceptable incidence of intraorbital recurrence and is presently not recommended. Ocular complications, including dry eye and cataract are frequently reported in patients that have long-term follow up. ${ }^{8}$ These localized complications need to be kept in mind by the treating oncologist.

\section{Immunotherapy: interferon (IFN-alpha)}

IFN-alpha has been used for the treatment of systemic lymphoma for more than 20 years. There are few reports of its local use for ocular lymphoma. One study treated 5 patients with intralesional IFN-alpha using an intensive protocol. ${ }^{9}$ An initial complete response was seen in all patients with stage I OAL, one patient with more advanced disease at presentation (stage IIA) died from systemic lymphoma. Long-term follow up studies are required to assess the value of this treatment.

\section{Immunotherapy: monoclonal antibody}

Rituximab is a monoclonal antibiotic against CD20 positive $\mathrm{B}$ cells, which is being considered as an alternative first line treatment for localized CD20 positive OAL to avoid the ocular complications of radiotherapy. Antibody-induced destruction of CD20 positive B cells can occur by apoptosis, complement mediated cytolysis and antibody-dependent, cell-mediated cytoxicity. It may be used instead of systemic steroids for benign lymphoid hyperplasia. Rituximab has also been used as monotherapy for localized EMZL/MALT, in some cases complete regression can be achieved. Initial responses are encouraging but the efficacy of rituximab is lower than that reported for gastric MALT lymphoma, ${ }^{10}$ as long-term distal relapse is seen in $50 \%$ of cases. Very few case series are published on the effect of single agent rituximab on ocular MALT/EMZL. Ferreri and associates achieved regression of MALT lymphoma using first line single agent rituximab in all 5 newly diagnosed patients; however early relapse was seen in 4 of the 5 patients. ${ }^{10}$ Therefore, close follow up intervals are required to detect early relapse when rituximab is used alone. Rituximab was not successful for the treatment of local relapse. ${ }^{10}$

Greater success is achieved when rituximab is used in combination with chemotherapy. Rituximab and chlorambucil were used as first-line therapy for 9 patients with newly diagnosed EMZL. Treatment achieved complete remission in $89 \%$ with a median follow up of 2 years. ${ }^{11}$

First-line chemotherapy is often treatment of choice for mantle cell OAL, as a high proportion of patients have 
systemic involvement at presentation. Encouragingly, rituximab containing chemotherapy for mantle cell OAL had a significantly better 5-year survival than patients receiving chemotherapy alone (83\% overall 5-year survival verses $8 \%$ ). ${ }^{12}$ Combination treatment with rituximab and chemotherapy or radioimmunotherapy may achieve a more durable local response and improve patient survival. ${ }^{11-13}$

\section{Chemotherapy}

Chemotherapy is reserved for treatment of OAL when there is systemic involvement, except for the high-grade DLBCL when systemic chemotherapy is first-line treatment even for stage I disease. The standard regimen is cyclophosphamide, doxorubicin, vincristine and prednisolone (CHOP). Systemic steriod alone does not offer effective long-term control. More recently chlorambucil and the purine analogs fludarabine, clardarabine and pentostatin have also been used. The Extranodal Lymphoma Study Group (IELSG) is currently recruiting patients to a clinical trial investigating the role of rituximab alone or in combination with chlorambucil for MALT lymphoma (IELSG \#19). ${ }^{14}$

\section{Systemic antibiotics}

Novel mechanisms of tumor pathogenesis have related lymphoma to infection leading to new approaches to diagnosis and treatment. Chronic antigen stimulation may result in an abnormal lymphoproliferative response that ultimately develops into lymphoma. This association is most profound for gastric MALT cell lymphoma, which is related to chronic gastritis from Helicobacter pylori infection in more than $90 \%$ of cases. ${ }^{15} \mathrm{H}$. pylori has been isolated from ocular lymphoma specimens. However, H. pylori eradication is not effective treatment for OA MALT lymphoma. ${ }^{16}$

Chlamydia psittaci infection has also been linked to OAL. Ferreri and associates ${ }^{17}$ identified C. psittaci in $80 \%$ of Italian OA MALT lymphoma specimens. In Korea, C. psittaci was isolated in $78 \%$ of OA MALT lymphoma specimens. ${ }^{18}$ Subsequent reports from South Florida, New York State, Chicago, Netherlands, Japan and France failed to identify DNA for C. psittaci in any of their OA MALT lymphoma specimens. ${ }^{19-24}$ There is wide geographical variation in the prevalence of $C$. psittaci infection in OA MALT lymphoma specimens. ${ }^{25}$ Of the European countries studied, the lowest rate of infection (12\%) was present in the UK.

Results following first line antibiotic treatment are variable. ${ }^{26}$ Abramson and coworkers ${ }^{27}$ documented a clinical response following antibiotic treatment in 3 patients with OA MALT lymphoma. Ferreri and associates ${ }^{28}$ recorded an objective response following oral doxycycline in 4 out of 9 patients with $C$. psittaci positive OA MALT lymphoma. Although, Grunberger and associates ${ }^{29}$ were unable to replicate these results. In a multicenter prospective trial, 27 patients with ocular adnexal MALT lymphoma were treated with oral doxycycline. C. psittaci DNA positive cases had an overall response rate of $64 \%$, the response was of short duration. ${ }^{30} \mathrm{~A}$ clinical response was also seen in $38 \%$ in $C$. psittaci DNA negative cases. ${ }^{30}$ Lack of response to antibiotic therapy may be a reflection of the biological and genetic heterogeneity of this disease. The Extranodal Lymphoma Study Group (IELSG) has activated a prospective trial (IELSG \#27) into OAL to explore the role of antibiotic treatment and to identify potential infectious agents. ${ }^{14}$

In summary, advances in our knowledge of the immunophenotypic and genetic alterations in lymphoma cell lines have led to a better understanding of the pathogenesis of the disease. The interplay between a possible infective agent and the immune response has allowed a new wave of treatment possibilities. Ongoing clinical trials will reveal the truth about new treatments. Staging the patient at diagnosis guides subsequent management and local treatments should be reserved for localized disease. However, the practical approach to the patient remains "first do no harm" and with this in mind ocular oncologists are tempted to administer an initial trial of oral antibiotics for stage 1 MALT lymphoma. Although, general blanket treatment with antibiotics should be discouraged unless there is proof of an infective agent. We recommend a diagnostic biopsy with immunophenotyping and genetic analysis to determine the grade of the lymphoma combined with PCR analysis to determine the presence of an infective agent. If $H$. pylori or $C$. psittaci infection is found a trial of oral doxycycline (100 mg twice daily for 3 weeks) is worthwhile. We have also seen some early impressive responses to systemic rituximab (weekly intravenous infusion over 6 weeks). However, close follow up is required as others have reported early local relapse with rituximab alone. ${ }^{10}$ At present, despite the ocular side effects, localized radiotherapy still remains the standard first-line treatment for stage I low-grade OAL.

\section{Disclosure}

The author declares no conflicts of interest.

\section{References}

1. Shields CL, Shields JA, Carvalho C, Rundle P, Smith AF. Conjunctival lymphoid tumors: clinical analysis of 117 cases and relationship to systemic lymphoma. Ophthalmology. 2001;108:979-984.

2. Tanimoto K, Kaneko A, Suzuki S, et al. Long-term follow-up results of no initial therapy for ocular adnexal MALT lymphoma. Ann Oncol. 2006; $17: 135-140$. 
3. Restrepo A, Raez LE, Byrne GE Jr, et al. Is central nervous system prophylaxis necessary in ocular adnexal lymphoma? Crit Rev Oncog. 1998;9:269-273.

4. Fung CY, Tarbell NJ, Lucarelli MJ, et al. Ocular adnexal lymphoma: clinical behavior of distinct World Health Organization classification subtypes. Int J Radiat Oncol Biol Phys. 2003;57:1382-1391.

5. Jenkins C, Rose GE, Bunce C, et al. Histological features of ocular adnexal lymphoma (REAL classification) and their association with patient morbidity and survival. Br J Ophthalmol. 2000;84:907-913.

6. Bhatia S, Paulino AC, Buatti JM, Mayr NA, Wen BC. Curative radiotherapy for primary orbital lymphoma. Int J Radiat Oncol Biol Phys. 2002;54:818-823.

7. Uno T, Isobe K, Shikama N, et al. Radiotherapy for extranodal, marginal zone, B-cell lymphoma of mucosa-associated lymphoid tissue originating in the ocular adnexa: a multiinstitutional, retrospective review of 50 patients. Cancer. 2003;98:865-871.

8. Liao SL, Kao SC, Hou PK, Chen MS. Results of radiotherapy for orbital and adnexal lymphoma. Orbit. 2002;21:117-123.

9. Blasi MA, Gherlinzoni F, Calvisi G, et al. Local chemotherapy with interferon-alpha for conjunctival mucosa-associated lymphoid tissue lymphoma: a preliminary report. Ophthalmology. 2001;108: 559-562.

10. Ferreri AJ, Ponzoni M, Martinelli G, et al. Rituximab in patients with mucosal-associated lymphoid tissue-type lymphoma of the ocular adnexa. Haematologica. 2005;90:1578-1579.

11. Rigacci L, Nassi L, Puccioni M, et al. Rituximab and chlorambucil as first-line treatment for low-grade ocular adnexal lymphomas. Ann Hematol. 2007;86:565-568.

12. Rasmussen P, Sjo LD, Prause JU, Ralfkiaer E, Heegaard S. Mantle cell lymphoma in the orbital and adnexal region. Br J Ophthalmol. 2009;93:1047-1051.

13. Shome D, Esmaeli B. Targeted monoclonal antibody therapy and radioimmunotherapy for lymphoproliferative disorders of the ocular adnexa. Curr Opin Ophthalmol. 2008;19:414-421.

14. IELSG. \#19 Multicenter randomized trial of chlorambucil versus chlorambucil plus rituximab versus rituximab alone in extranodal marginal zone B-cell lymphoma of mucosa associated lymphoid tissue (MALT lymphoma). \#27 A clinico-pathological phase II study with translational elements to investigate the possible infective causes of MALT lymphoma of the ocular adnexa with particular reference to Chlamydia species and the effects of treatment with tetracycline. Protocol available via the IELSG Trial Coordination Centre. URL http://www.ielsg.org/trialsonfr.html.

15. Wotherspoon AC, Ortiz-Hidalgo C, Falzon MR, Isaacson PG. Helicobacter pylori-associated gastritis and primary B-cell gastric lymphoma. Lancet. 1991;338:1175-1176.
16. Ferreri AJ, Ponzoni M, Viale E, et al. Association between Helicobacter pylori infection and MALT-type lymphoma of the ocular adnexa: clinical and therapeutic implications. Hematol Oncol. 2006;24:33-37.

17. Ferreri AJ, Guidoboni M, Ponzoni M, et al. Evidence for an association between Chlamydia psittaci and ocular adnexal lymphomas. J Natl Cancer Inst. 2004;96:586-594.

18. Yoo C, Ryu MH, Huh J, et al. Chlamydia psittaci infection and clinicopathologic analysis of ocular adnexal lymphomas in Korea. Am J Hematol. 2007.

19. Rosado MF, Byrne GE Jr, Ding F, et al. Ocular adnexal lymphoma: a clinicopathologic study of a large cohort of patients with no evidence for an association with Chlamydia psittaci. Blood. 2006;107:467-472.

20. Vargas RL, Fallone E, Felgar RE, et al. Is there an association between ocular adnexal lymphoma and infection with Chlamydia psittaci? The University of Rochester experience. Leuk Res. 2006;30:547-551.

21. Zhang GS, Winter JN, Variakojis D, et al. Lack of an association between Chlamydia psittaci and ocular adnexal lymphoma. Leuk Lymphoma. 2007;48:577-583.

22. Mulder MM, Heddema ER, Pannekoek Y, et al. No evidence for an association of ocular adnexal lymphoma with Chlamydia psittaci in a cohort of patients from the Netherlands. Leuk Res. 2006;30:1305-1307.

23. Daibata M, Nemoto Y, Togitani K, et al. Absence of Chlamydia psittaci in ocular adnexal lymphoma from Japanese patients. Br J Haematol. 2006;132:651-652.

24. de Cremoux P, Subtil A, Ferreri AJ, et al. Re: Evidence for an association between Chlamydia psittaci and ocular adnexal lymphomas. J Natl Cancer Inst. 2006;98:365-366.

25. Chanudet E, Zhou Y, Bacon CM, et al. Chlamydia psittaci is variably associated with ocular adnexal MALT lymphoma in different geographical regions. J Pathol. 2006;209:344-351.

26. Husain A, Roberts D, Pro B, McLaughlin P, Esmaeli B. Meta-analyses of the association between Chlamydia psittaci and ocular adnexal lymphoma and the response of ocular adnexal lymphoma to antibiotics. Cancer. 2007;110:809-815.

27. Abramson DH, Rollins I, Coleman M. Periocular mucosa-associated lymphoid/low grade lymphomas: treatment with antibiotics. $\mathrm{Am} \mathrm{J}$ Ophthalmol. 2005;140:729-730.

28. Ferreri AJ, Ponzoni M, Guidoboni M, et al. Regression of ocular adnexal lymphoma after Chlamydia psittaci-eradicating antibiotic therapy. J Clin Oncol. 2005;23:5067-5073.

29. Grunberger B, Hauff W, Lukas J, et al. 'Blind' antibiotic treatment targeting Chlamydia is not effective in patients with MALT lymphoma of the ocular adnexa. Ann Oncol. 2006;17:484-487.

30. Ferreri AJ, Ponzoni M, Guidoboni M, et al. Bacteria-eradicating therapy with doxycycline in ocular adnexal MALT lymphoma: a multicenter prospective trial. J Natl Cancer Inst. 2006;98:1375-1382.
Clinical Ophthalmology

\section{Publish your work in this journal}

Clinical Ophthalmology is an international, peer-reviewed journal covering all subspecialties within ophthalmology. Key topics include: Optometry; Visual science; Pharmacology and drug therapy in eye diseases; Basic Sciences; Primary and Secondary eye care; Patient Safety and Quality of Care Improvements. This journal is indexed on Submit your manuscript here: http://www.dovepress.com/clinical-ophthalmology-journal

\section{Dovepress}

PubMed Central and CAS, and is the official journal of The Society of Clinical Ophthalmology (SCO). The manuscript management system is completely online and includes a very quick and fair peer-review system, which is all easy to use. Visit http://www.dovepress.com/ testimonials.php to read real quotes from published authors. 